\title{
Is It Good To Know Or Not To Know? Is There Any Effect of Information About Cancer Diagnosis and Treatment on Anxiety Levels of Adolescents with Cancer and Their Parents
}

\section{Bilgilendirmek mi, Bilgilendirmemek mi İyi? Kanser Tanı ve Tedavisi Hakkında Bilgilendirmenin, Kanser Tanısı Alan Adölesanlar ve Ebeveynlerinin Anksiyete Düzeylerine Etkisi}

\author{
Meric Kaymak Cihan ${ }^{1}$, Neriman Sarı ${ }^{1}$, Hayrıye Dilek Hamurcu ${ }^{2}$, Nurseven Karaman ${ }^{1}$, Nurhan Baş ${ }^{1}$, İncı \\ Ergürhan Illhan ${ }^{1}$
}

${ }^{1}$ Dr. Abdurrahman Yurtaslan Ankara Onkoloji Eğitim ve Hastanesi Çocuk Hematoloji-Onkoloji Bölümü, Ankara,Türkiye

${ }^{2}$ Dr. Abdurrahman Yurtaslan Ankara Onkoloji Hastanesi Psikiyatri Bölümü, Ankara

Dergiye Ulaşma Tarihi:16.11.2018 Dergiye Kabul Tarihi:22.04.2019 Doi: 10.5505/aot.2019.59672

\section{ÖZET}

GíRIŞ̧ ve AMAÇ: Bu çalışmada adölesan dönemdeki pediatrik onkoloji hastalarının ve ebeveynlerinin, hastalık tanısı, tedavi süreci ve alacağı kemoterapi hakkında bilgilendirilmelerinin, çocuk ve ebeveynlerin kaygı düzeylerine etkisinin araştıılması hedeflenmiştir.

YÖNTEM ve GEREÇLER: Çalışmaya, 2015 ile 2016 yılları arasında, Dr. Abdurrahman Yurtaslan Ankara Onkoloji Eğitim ve Araştırma Hastanesi Çocuk Hematoloji-Onkoloji Bölümü'nde yeni tanı almış, yaşları 14-18 arasında değişen 55 çocuk kanser hastası ve yaşları 30-50 arasında değişen 58 ebeveyn alındı. Yatırılarak kemoterapi alması planlanan çocuk ve ebeveynlere, hastalık ve tedavi hakkında bilgi verildi. Hastalık öncesi rutin hayatlarındaki genel anksiyete düzeylerini ölçmek için STAI-II (süreklilik anksiyete), hastalık belirtileri başlamasından kanser tanı ve tedavisi konusunda bilgilendirme öncesi ve sonrası durumsal kaygı durumunu ölçmek için de STAI-I (durumlulukanksiyete) ölçekleri kullanıldı. Yapılan bilgilendirmenin anksiyete düzeylerine etkisi araştırıldı.

BULGULAR: Hastalık belirtileri başlamadan önceki rutin hayatlarında STAI-II ölçeğiyle değerlendirilen süreklilik anksiyete düzeylerinin ortancası hastalarda 38 puan (25-67), ebeveynlerinde 45 puan (26-65) olarak saptandı. $(\mathrm{p}<0,001)$. Bilgilendirme öncesi durumsal kaygıyı ölçen STAI-I ortanca puanları hastalarda 38 (23-73), ebeveynlerde 48 puan (28-65) olarak bulundu (p: 0.001). Bilgilendirme görüşmesi yapıldıktan sonra STAI-I puanlarının ortancası hastalarda 38 puan (26-67), ebeveynlerinde 42 puandı (23-68) (p: 0,067). Bilgilendirme öncesi ve sonrası çocukların kaygı düzeyleri değişmezken $(\mathrm{p}=0,679)$, ebeveynlerin kaygı düzeylerinde bilgilendirme sonrasında istatistiksel olarak anlamlı bir düşüş gözlendi $(\mathrm{p}=0,01)$.

TARTIŞMA ve SONUÇ: Çalışmamıza katılan ebeveynlerin rutin hayatlarındaki genel kaygı düzeyleri hafiforta düzeyde olup çocuklarına göre daha kaygılı oldukları tespit edilmiştir. Hastalık belirtilerinin başlamasından bilgilendirme görüşmesine kadar olan zaman dilimindeki durumsal kaygı düzeylerine bakıldığında ebeveynlerin çocuklara göre daha kaygılı oldukları görülmüştür. Bilgilendirme ebeveynlerin kaygı düzeylerini azaltmış, çocukların kaygı düzeylerine ise etkisi olmamıştır.

Anahtar Kelimeler: Adölesan kanser, Anksiyete, Bilgilendirme.

\begin{abstract}
INTRODUCTION: In this study, it was aimed to investigate the effect of providing information about the diagnosis, treatment process and chemotherapy to adolescent pediatric oncology patients and their parents on the anxiety levels of them.

METHODS: Between 2015 and 2016; fifty-five children aged between 14 and 18 years and their parents $(n=55$; age: 30-50 years) were included in the study. Children who were planned to receive chemotherapy and their parents were informed about the disease and treatment. STAI-II (continuity anxiety) scale was used to measure the general anxiety levels in pre-disease routine life. STAI-I (state anxiety) was used to measure the state of situational anxiety before and after information about the diagnosis and treatment of cancer. The effect of informing on anxiety levels was investigated.
\end{abstract}

RESULTS: The median of continuity anxiety levels evaluated with STAI-II scale in the routine life before the onset of the disease symptoms was 38 points (25-67) in patients and 45 points (26-65) in their parents ( $p$ $<0.001)$. The mean STAI-I median scores were 38 (23-73) in patients and 48 (28-65) in parents (p: 0.001). After the informative interview the median of the STAI-I scores was 38 points (26-67) in the patients and 42 points in 
the parents (23-68) (p: 0,067). While the anxiety levels of the children before and after the informations did not change $(\mathrm{p}=0.679)$, a statistically significant decrease was observed in the anxiety levels of the parents $(\mathrm{p}=$ $0.01)$.

DISCUSSION AND CONCLUSION: The general anxiety levels of the parents who participated in our study were mild to moderate in their routine lives and they were found to be more anxious than their children. When we look at the state-related anxiety levels in the period from the onset of disease symptoms to the informative interview, it was observed that parents were more anxious than children. Informing decreased the anxiety levels of the parents and had no effect on the anxiety levels of the children.

Keywords: Adolescent cancer, Anxiety, Information.

\section{GİRIŞ}

Kanser insan yaşamını ciddi bir şekilde etkileyen, ağır ve kronik bir hastalıktır. Türkiye'de her yıl yaklaşık 2500-3000 çocuk kanser tanısı almaktadır. Çocuklarda görülen kanser tipleri, tedaviye yanıt oranları ve uzun süreli sağkalım açısından erişkin kanserlerinden çok farklılıklar göstermektedir. Amerika'da Ulusal Kanser Enstitüsü US-SEER (United States Surveillance Epidemiology and End Results) programı verilerine göre 0-19 yaş için 5 yıllık yaşam oranları 1975 'de $\% 60$ civarında iken 1996 'da \%80'lere yükselmiştir (1). Tedavi sürecinde ve sonucundaki belirsizlikler çocukluk çağı kanserlerinde hem çocukları hem de ebeveynleri derinden etkilemektedir. $\mathrm{Bu}$ süreç ailelerin sosyal ve psikolojik olarak birçok yeni sorunla karşılaştıkları bir dönem olabilmektedir. Öte yandan hastalık hakkında bilgilendirilmenin, hastalıkla baş edebilme yetisini artırdığı, belirsizlik ve negatif duyguları azalttığı, hastalı tedavisine uyum sürecini ve tedavide karar aşamasına katılımı sağladığı, normal yaşamı devam ettirmeye katkıda bulunduğu (27) ve kaygı ile duygu durum değişikliklerini azalttığı $(8,9)$ yapılan çalışmalarla gösterilmiştir.

$\mathrm{Bu}$ çalışmada adölesan dönemdeki pediatrik onkoloji hastalarının ve ebeveynlerinin, hastalık tanısı, tedavi süreci ve alacağı kemoterapi hakkında bilgilendirilmelerinin, kaygı düzeylerine etkisinin araştırılması hedeflenmiştir.

\section{MATERYAL METOT}

Çalışmaya Dr. Abdurrahman Yurtaslan Ankara Onkoloji Eğitim ve Araştırma Hastanesi Çocuk Hematoloji-Onkoloji Bölümü'nde, 2015 ile 2016 yılları arasında ilk kez kanser tanısı almış olan, yaşları 14-18 arasında değişen 55 adölesan kanser hastası ve bu hastaların yaşları 30-50 arasında değişen 58 ebeveyni (anne veya baba) alındı. Üç hastanın anne ve babası beraber gelmesi nedeni ile ikisi birden değerlendirildi. Anne ve babası olmayayn hasta yoktu. Hastalar patoloji tanıları çıktıktan sonra polikliniğe başvurdukları gün araştırmacı ile yalnız olarak ayrı bir görüşme odasında hem sözel hem de yazılı olarak hastalık tanısı, tedavi süreci, kemoterapi etki ve yan etkileri hakkında bilgilendirildi. Bütün hastaların bilgilendirmesi aynı klinisyen tarafindan yapıldı. Anne ve babaya ayrica aynı klinisyen tarafından bilgilendirme yapıldı. Hastaların sonraki takip ve tedavileri yine aynı klinisyen tarafından devam edildi. Yarı yapılandırılmış bir görüşme formu ile olguların sosyodemografik verileri elde edildi. Bilgilendirme öncesi ve bilgilendirme sonras1, anket yöntemi ile sosyodemografik veri formu ve Durumluk-Süreklilik Kaygı Envanteri (STAI I-II, State-TraitAnxiety Inventory) uygulanarak, anksiyete düzeyleri tespit edildi. Yapilan bilgilendirmenin anksiyete düzeylerine etkisi araştırıldı.

Hastalık öncesi rutin hayatlarındaki genel anksiyete düzeylerini ölçmek için STAIII (süreklilik anksiyete), kanser tanı ve tedavisi konusunda bilgilendirme öncesi ve sonras1 kaygı durumunu ölçmek için de STAI-I (durumluluk anksiyete) ölçekleri kullanıldı. Daha önceden bilinen bir psikiyatrik rahatsızlığ1 olan ve/veya halen antidepresan veya psikotrop ilaç kullanan hastalar, ikincil kanser teşhisi olanlar, testleri anlama yeterliliğine sahip olmayan (mental retardasyon, psikotik bozukluk vs.) hastalar ve ebeveynler çalışma dışı bırakıldı. Kaygı düzeyi yüksek olan hasta ve ebeveynler psikiyatri bölümüne yönlendirildi. Ancak tedavi süreçlerinin kaygı düzeylerine etkisi ve kayg1 tedavisi araştırma konusu olarak alınmadı.

Çalışma için yerel etik kurul onayı alındı. Çalışmaya katılmayı kabul eden hastalar ve ebeveynlerinden bilgilendirilmiş onam alındı.

Sosyodemografik Veri Toplama Formu: Çalışma ekibince geliştirilen yarı yapılandırılmış görüşme formunda olguların 
yaş, cinsiyet, eğitim durumu, kardeş sayısı ve tanısı not edildi. Anne ve babalara, yaş, eğitim durumu, çocuk sayısı ve meslekleri sorularak not edildi.

STAI (State-Trait Anxiety Inventory=Durumluk-Süreklilik Kayg1 Envanteri): Spielberger ve arkadaşları (1970) tarafından geliştirilen bu envanter her biri 20 sorudan oluşan sürekli ve durumluk olmak üzere iki alt ölçekten oluşmaktadır (10). On dört yaş üstü bireylere uygulanabilmektedir. Durumluk kaygı ölçeği, bireyin belirli bir anda ve belirli koşullarda kendini nasıl hissettiğini, sürekli kayg1 ölçeği ise bireyin içinde bulunduğu durum ve koşullardan bağımsız olarak kendini nasıl hissettiğini belirler. Durumluluk ve Süreklilik Kaygı Envanterinin Türkçe 'ye adaptasyonu, geçerlilik ve güvenirlilik çalışması Öner ve Le Compte (1983) tarafindan yapılmıştır. STAI ölçeği puanlandirılmas1 20-80 puan arasinda olup, 20 puan 'hiç kaygı yok', 80 puan 'en yüksek kaygı' puanı olarak değerlendirilmektedir.

\section{Istatistik}

Çalışma sonucu elde edilen tüm verilerin değerlendirilmesinde "SPSS For Windows 17.0 Standart Version" istatistik program1 kullanıldı. Elde edilen sayısal verilerin karşılaştırmasında (ölçek sonuçları) MannWhitney $U$ testi kullanıld1. Bilgilendirme öncesi ve sonrası anksiyete ölçeklerinin karşılaştırılması Wilcoxon signed-rank testi ile yapıldı. Eğitim düzeyi ve tanılara göre kayg1 ölçeğinin karşılaştırılması Kruskal-Wallis testi ile yapıld1. Anlamlılık düzeyi olarak $\mathrm{p}<0.05$ kabul edildi.

\section{SONUÇLAR}

Yaşları 14-18 arasında değişen toplam 55 hasta ve 58 ebeveyn çalışmaya dâhil edildi. Hastalara ve ebeveynlere ait sosyodemografik özellikler Tablo 1 ve 2'de gösterilmektedir. Süreklilik kayg1 veya genel hayatlarındaki kayg1 düzeylerine bakıldığında ebeveynlerin çocuklardan daha kaygıll oldukları görüldü (hasta ortanca kayg1 ölçeği 38, ebeveyn kayg1 ölçeği 45; p=0,01). Bilgilendirme öncesi ve sonrası çocukların kaygı düzeyleri değişmezken (Tablo $1, \mathrm{p}=0,679$ ), ebeveynlerin kayg1 düzeylerinde bilgilendirme sonrasında istatistiksel olarak anlamlı bir düşüş gözlendi
(Tablo 2, p=0,01). Bilgilendirme öncesi anne ve babaların kayg1 düzeyleri farklı bulunmadı (Tablo 3, p=0,364). Bilgilendirme sonras1 ise annelerin kayg1 düzeyleri babalardan daha yüksek bulundu ancak aradaki fark istatistiksel olarak anlamlı değildi (Tablo 3, $\mathrm{p}=0,06$ ).

Tablo 1: Hastalara ait demografik veriler ve STAI puanlamaları

\begin{tabular}{|c|c|c|}
\hline Cinsiyet (Kız) & $\begin{array}{l}26 / 55(\% \\
37,7)\end{array}$ & \\
\hline Yaş (median) & $15(14-18)$ & \\
\hline Osteosarkom & $16(\% 23,2)$ & \\
\hline Ewing sarkom & $12(\% 17,4)$ & \\
\hline Hodgkin Lenfoma & $7 \quad(\% 10,1)$ & \\
\hline Rabdomyosarkom & $5(\% 7,2)$ & \\
\hline Akut lenfoblastik lösemi & $3(\% 4,3)$ & \\
\hline Non HodgkinLenfoma & $3(\% 4,3)$ & \\
\hline Diğer & $9 \quad(\% 16,4)$ & \\
\hline Kardeș sayıs1 (median) & $3(1-10)$ & \\
\hline Eğitim Düzeyi & & \\
\hline İlkokul & $13(\% 18,8)$ & \\
\hline Ortaokul & $16(\% 23,2)$ & \\
\hline Lise & $25(\% 36,2)$ & \\
\hline Üniversite & $1(\% 1,4)$ & \\
\hline STAI-II (median) & $38(25-67)$ & \\
\hline $\begin{array}{l}\text { Bilgilendirme öncesi STAI-I } \\
\text { (median) }\end{array}$ & $38(23-73)$ & \multirow[t]{2}{*}{$\mathrm{p}=0,679 *$} \\
\hline $\begin{array}{l}\text { Bilgilendirme sonrası STAI-I } \\
\text { (median) }\end{array}$ & $38(26-67)$ & \\
\hline $\begin{array}{l}\text { STAI: State Trait Anxiety, } \\
\text { bilgilendirme } \\
\text { kars1lastır1lmas1 }\end{array}$ & $\begin{array}{l}\text { Bilgilendir } \\
\text { STAI-I }\end{array}$ & $\begin{array}{l}\text { öncesi ve } \\
\text { nuçlarının }\end{array}$ \\
\hline
\end{tabular}

Tablo 2: Ebeveynlere ait demografik veriler ve STAI puanlamaları

\begin{tabular}{|l|l|l|}
\hline Ebeveyn ( & $\begin{array}{l}\text { Anne }(\mathrm{n}=38, \\
\% 62,3)\end{array}$ & $\begin{array}{l}\text { Baba }(\mathrm{n}=20, \\
\% 37,7)\end{array}$ \\
\hline Yaş (median) & $37,5(30-49)$ & $43(31-50)$ \\
\hline Meslek & $2(\% 5,3)$ & $2(\% 10,0)$ \\
Memur & $2(\% 5,3)$ & $4(\% 20,0)$ \\
İşçi & $0(\% 0,0)$ & $1(\% 5,0)$ \\
Emekli & $0(\% 0,0)$ & $10(\% 50,0)$ \\
Serbest & $0(\% 0,0)$ & $3(\% 13,0)$ \\
Esnaf & $34(\% 89,5)$ & $0(\% 0,0)$ \\
Ev Hanımı & $3(1-6)$ & $3(1-9)$ \\
\hline Çocuk sayıs1 (median) & \multicolumn{2}{|c|}{$0(\% 0,0)$} \\
\hline Eğitim Düzeyi & $3(\% 7,9)$ & $11(\% 55,0)$ \\
Okur yazar değil & $23(\% 60,5)$ & $1(\% 5,0)$ \\
İlkokul & $4(\% 10,5)$ & $7(\% 35.0)$ \\
Ortaokul & $6(\% 15,8)$ & $1(\% 5,0)$ \\
Lise & $2(\% 5,3)$ & \\
Üniversite & \multicolumn{2}{|c|}{$45(26-65)$} \\
\hline STAI-II (median) \\
(Tüm ebeveynler)
\end{tabular}


STAI: State Trait Anxiety, *Bilgilendirme öncesi ve bilgilendirme sonrası STAI-I sonuçlarının

karşılaştırılması

Tablo 3: Anne ve babaların bilgilendirme öncesi ve sonrası STAI puanlandırmaları

\begin{tabular}{|l|l|l|l|}
\hline & Anne & Baba & $p$ \\
\hline $\begin{array}{l}\text { STAI-II } \\
\text { (mean) }\end{array}$ & 31,71 & 25,30 & 0,169 \\
\hline BÖ STAI-I & 30,96 & 26,73 & 0,364 \\
\hline BS STAI-I & 33,89 & 21,15 & 0,06 \\
\hline
\end{tabular}

STAI: State Trait Anxiety

\section{TARTIŞMA}

Çocukluk çă̆1 kanserlerinde yaşam beklentisinin artmasiyla birlikte, hayat kalitesi üzerine yapılan çalışmaların sayısı ve farkındalığı da artmıştır. Kanserli çocuk ve adölesanlarda iyi olma hali öncelikle kendini tanıma ve kendini anlamadan geçmektedir. Kanserli çocukların ve adölesanların hastalıkları hakkında bilgilendirilmeleri özgüven duygusunu geliştirirken duygusal psikososyal olarak iyilik hali için olanak sağlar $(2,11)$. Bilgilendirilen adölesan kanser hastalarının bilgilendirilmeyenlere göre daha az depresif bozukluğu olduğu (7) ve hastalıkla baş etme yetilerinin daha fazla olduğu çalışmalarla gösterilmiştir (12). Last ve arkadaşları (13), hastalıkları hakkında açık olarak bilgilendirilen adölesan kanser hastalarının kaygı düzeylerinin daha düşük olduğunu buldular.

Çocuğunda kanser olan ebeveynlerin gerginlik ve belirsizlik içinde oldukları ve bunların da psikososyal sorunlar, kaygı ve depresif bozuklukları beraberinde getirdiği bilinmektedir (14). Ebeveynler en fazla, çocuklarına bakımlarında dikkat etmeleri gereken noktalar, hastalık süreci, tedavisi, sağkalım gibi konularda bilgilendirmeye ihtiyaç duymaktadırlar. Davis ve Fallowfield (15), ebeveynlerin hastalığa uyum süreçlerinin karmaşık bir süreç olduğunu belirterek, bu süreçte hastalıkla ilgili bilgi edinme ile, çocuklarına karşı davranış ve hastalığa uyum süreci arasında olumlu bir ilişki olduğunu ifade etmiştir. Hizel ve ark.(16) çalışmalarında, annelerin kanser ile ilgili bilgilerinin yetersiz, korku ve kaygılarının ise çok fazla olduğunu saptamışlardır. Yapılan çalışmalarda bilgilerin medya ve/veya arkadaşlardan edinilmesinin yerine, sağlık profesyonellerinden alınmasının daha faydalı olacağı, ailelerin bilgilendirilmesi ile kaygının azaltılabileceği ifade edilmiştir (17). Bizim çalışmamızda da bilgilendirme öncesinde, ebeveynlerin kayg1 ölçekleri, çocuklardan belirgin daha yüksekti. Bilgilendirme sonras1 ebeveynlerin STAI-I anksiyete ölçeğinde istatistiksel olarak anlamlı düşüş gözlendi. Çalışmamızda bilgilendirme sonras1 ebeveynlerin kayg1 düzeylerinin düşmesinde pek çok etken rol almış olabilir. Bunlardan birincisi bilgilendirmeyi yapan tedavi ekibinin hasta ve ebeveyne kanser tanısının nasıl söylenmesi gerektiği konusunda deneyimli olmas1, bilgilendirmeyi yaparken empatik bir yaklaşım ve umut aşılayarak bilgiyi aktarması, hastalık ve tedavi ile ilgili bilgi donanımının iyi olması olabilir. Diğer bir etken çalışmanın yapıldığ 1 Dr. Abdurrahman Yurtaslan Ankara Onkoloji Eğitim ve Araştırma Hastanesine Türkiye'nin pek çok ilinden ayırıcı tanı için hasta sevk edilmekte, kanser tanıs1 araştırılırken, ebeveynler çocuklarıyla birlikte ileri tetkik ve tedavi için bulundukları ilden ayrılmak durumunda kalabilmekte, bu araştırma süreci bazen beklenenden çok daha uzun bir zaman dilimini alabilmekte, bu belirsizlik süreci ebeveynlerin kaygılarını artırabilmektedir. Ebeveynlerin tanı ve tedavi hakkinda bilgilendirilmesiyle, belirsizlik belli bir oranda azalmakta, ebeveynler çocuklarının tedavi süreçlerine odaklanmaktadır. Aynı zamanda bilgilendirme sayesinde aileler gerek kanserli çocuklarının gerekse sağlıklı çocuklarının bakımı, ihtiyaçları ve diğer sosyal sorunlarıyla baş edebilmek için gerekli kaynaklarını yeniden gözden geçirmekte ve yeni bir düzenleme yaparak kısmen de olsa hayatlarındaki belirsizliklerin bir kısmını yeniden düzenleme çabası içine girmektedirler. $\mathrm{Bu}$ etkenler, bilgilendirme sonrasi ailelerdeki kayg1 düzeyinin azalmasında etkili olmuş olabilir. Çalışmamızda hastaların kaygı ölçeklerinde bilgilendirme ile değişiklik izlenmedi. Kanser tanısı sonrası ortaya çıkan tepkileri, Elizabeth Kübler Ross beş evrede tanımlamıştır. Bu evreler; inkâr, öfke, pazarlık, depresyon ve kabullenmedir (18). Bizim çalışmamızda; bilgilendirme sonrası hastaların kaygı düzeylerinde değişiklik olmaması, hastaların kanser tanısı almış olmanın yarattığ kaygıyla baş etmek için inkar savunma mekanizmasını kullanmış olmalarıla açıklanabilir. Kanser tanısının yarattığı kaygı kısmi olarak yok sayılarak baş edilmiş olabilir. 
$\mathrm{Bu}$ nedenle kanser tanısı alan çocuklarda kaygı ölçeğinde bilgilendirme öncesi ve sonrası fark ortaya çıkmamış olabilir.

Kanserli çocukların ebeveynlerinin, hastalıkla baş edebilme yetilerinin gelişmesi, çocuklarına daha iyi bakım sağlayabilme ve hastalıkla ilgili belirsizliklerin ortadan kalkması, psikososyal sorunların oluşmaması için bilgilendirilmeleri önemlidir. Vetsch ve arkadaşlarının (19) yaptıkları ve 2015 yılında yayınladıkları çalışmada, kanserli çocukların ebeveynlerinin çoğunlukla sözel olarak bilgilendirildikleri ancak ailelerin uzun dönem yan etkiler, tedavi planı gibi konularda daha ayrıntılı ve uzun süreçli bilgilendirmeye ve yazılı olarak bilgilendirmeye ihtiyaç duydukları tespit edildi. Biz hastalarımıza ve ebeveynlerine, hem sözel hem de yazılı olarak, hastalik tanısını, tedavi planını ve yan etkileri anlatan bir bilgilendirme formu ile bilgilendirme yaptık. Yapılan iki çalışmada ebeveynlerin bilgilendirilmelerinin kayg1lar1 üzerine etkisi tam gösterilememiştir $(20,21)$. Bizim çalışmamı bilgilendirme ile ebeveynlerin kayg1 ölçeklerinde gerileme olduğunu göstermiştir. Annelerin genel olarak kayg1 düzeyleri babalara göre daha yüksek bulunmuştur (Tablo 3) ancak bu istatistiksel anlamlı bir yükseklik değildir. Ayrıca bilgilendirme sonrası annelerin kaygı ölçekleri babalara göre daha yüksek kalmıştır. $\mathrm{Bu}$ da annelerin çocukların bakımı ile birebir daha fazla ilgilenmeleri ile ilişkili olabilir.

Ringer ve arkadaşları (22) yaptıkları çalışmada, pediatrik onkoloji alanında eğitim almış hemşireler aracılığ tanıs1 almış ebeveynlere, tedavi sürecinde her 3 haftada bir birer saatlik görüşmeler ile bilgilendirme yapmışlardır. Görüşmelerde ebeveynlerin belirledikleri ve en çok ihtiyaç duydukları konular üzerinde durulmuştur. Çalışma sonucunda ebeveynler görüşmelerden büyük ölçüde fayda gördüklerini ifade etmişlerdir. Ancak çalışma sonunda ebeveynlerin emosyonel stres düzeylerinde bir değişiklik izlenmemiştir (22). Bizim çalışmamız hastalığın ilk tanısı konulduktan sonraki bilgilendirme sürecini içermektedir. Tedavi süreci boyunca hastaların ve ebeveynlerin farklı konularda bilgilendirilme ihtiyaçlarını ve buna yönelik bir ara bilgilendirmenin kaygı düzeylerine etkisini biz çalışmamızda incelemedik. Ancak zaman içerisinde hastalığın tedavi sırasındaki durumu ve çocukların hastanede uzun yatış süreleri ile birlikte ailelerde farklı kaygilar ortaya çıkabilmektedir. $\mathrm{Bu}$ alanda uzun süreçli ve bilgilendirmenin hastalığın seyrine etkisini araştıran çalışmaların yapılmasına ihtiyaç olduğunu düşünmekteyiz.

\section{SONUÇ}

Kanser hastalığg ve tedavisi ile ilgili bilgi vermek ebeveynlerin kayg1 düzeylerini azaltmış, çocukların kaygı düzeylerini ise etkilememiştir. Hastalıkla baş edebilme yetisi ve sürecin açıklığa kavuşması açısından bilgilendirme oldukça önemlidir. Hastalı̆̆ın tedavi sürecindeki yapılacak aralıklı bilgilendirmelerin, ebeveynler ve hastalar üzerindeki etkilerini inceleyen ayrıntılı çalışmalara ihtiyaç vardır.

\section{REFERANSLAR}

1. Gurney JG, Bondy ML. Epidemiology of childhood cancer. In: Pizzo PA, Poplack DG, eds. Principles and Practice of Pediatric Oncology. 5th ed. Philedelphia: Lippincott-Roven; 2006. p.1-13.

2. Dunsmore J, Quine S. Information, support, and decision-making needs and preferences of adolescents with cancer: implications for health professionals. J Psychosoc Oncol 1995;13(4):39-56.

3. Van Dongen-Melman JEWM, Pruyn JFA, Van Zanen GE, Sanders Woudstra JAR. Coping with childhood cancer: a conceptual view. J Psychosoc Oncol 1986;4:147-161.

4. Claflin CJ, Barbarin OA. Does "telling" less protect more? Relationships among age, information disclosure, and what children with cancer see and feel. J Pediatr Psychol 1991;16(2):169-191.

5. Ohanian NA. Informational needs of children and adolescents with cancer. J Pediatr Oncol Nurs1989;6(3):94-97.

6. Kamphuis RP. The concept of quality of life in pediatric oncology. In:Aaronson NK, Beckmann J, eds. The Quality of Life of Cancer Patients.New York: Raven, 1987.p.141-51.

7. Kvist SBM, Rajantie J, Kvist M, Simes MA. Aggression: the dominant psychological response in children with malignant disease. Psychol Rep1991;68(3Pt 2):1139-1150.

8. Meredith C, Symonds P, Webster L, et al. Information needs of cancer patients in west Scotland: cross sectional survey of patients' views. BMJ 1996;313(7059):724-726. 
9. Rainey LC. Effects of preparatory patient education for radiation oncology patients. Cancer 1985;56(5):1056-1061.

10. Spielberger CD, Gorsuch RL, Lushene RE. Manual for State-TraitAnxiety Inventory: Consulting Psychologist 1970

11. Neville $K$. The relationships among uncertainty, social support, and psychological distress in adolescents recently diagnosed with cancer. J Pediatr Oncol Nurs 1998;15(1):37-46.

12. Derdiarian, A. Informational needs of recently diagnosed cancer patients: A theoretical framework, Part 1. Cancer Nursing1987;10(2):107-115.

13. Last BF, van Veldhuizen AM. Information about diagnosis and prognosis related to anxiety and depression in children with cancer aged 8-16 years. Eur J Cancer 1996;32A(2):290-294.

14. Björk, M, Wiebe, T, Hallström, I. Striving to survive: families' lived experiences when a child is diagnosed with cancer. Journal of Pediatric Oncology Nursing 2005;22:265-275.

15. Davis H, Fallowfield L. Counselling and communication In health care: the current situation. In: Davis H, Fallowfield L, eds. Counselling and communication in healthcare. Chichester: Wiley, 1991.

16. Hizel S, Toprak Ş, Albayrak M, Sanlı C, Koçak Ü. Kanserli Çocuklar Hakkında Anadolu'nun Kirsal Bir İlindeki Annelerin

23. Experiences and effects. Eur J Oncol Nurs 2015;19(3):318-24.
Bilgi, Tutum ve Davranışları. Gazi Tıp Dergisi 2009:20(1):3-6.

17. Swallow VM, Jacoby, A. Mothers' evolving relationship with doctors and nurses during the chronic childhood illness trajectory. Journal of Advance Nursing 2001;36(6):755-764.

18. Kubler-Ross E. The family physician and the dying patient. Can Fam Physician 1972;18(10):79-83

19. Vetsch J, Rueegg CS, Gianinazzi ME, Bergstra"sser E, von der Weid NX, Michel G, Swiss Paediatric Oncology Group (SPOG). Information Needs in Parents of Long-Term Childhood Cancer Survivors. Pediatr Blood Cancer 2015;62(5):859866.

20. Hashemi F, Shokrpour, N, The impact of education regarding the needs of pediatric leukemia patients' siblings on the parents' knowledge and practice. The Health Care Manager 2010;29(1):75-79.

21. Othman, A, Blunden, S, Mohamad, N, Mohd Hussin, ZA, Jamil Osman Z. Piloting a psycho-education program for parents of pediatric cancer patients in Malaysia. 2010;19(3):326-331

22. Ringnér A, Karlsson $\mathrm{S}$, Hällgren Graneheim U. A person-centred intervention for providing information to parents of children with cancer. 